\title{
Difficulty of Change framework and/or register among common core students experimental sciences and the first year mathematical sciences at the high school level. Morocco: Didactic Engineering.
}

\author{
Abdelouahed El Maroufi ${ }^{1}$, Mohammed Mouradi ${ }^{2}$, Monsef Zaki ${ }^{3}$ \\ ${ }^{I}$ Interdisciplinary laboratory of Search in Didactics of the Sciences and Techniques(LIRDST) \\ ${ }^{2}$ Faculty of the sciences Dhar El Mahraz,Sidi Mohamed Ben Abdellah-Fès university,Fes Atlas-Fès-Maroc
}

\begin{abstract}
In charge of teaching mathematics at high school, we wanted to explore the changes of frameworks and/or registers in teaching mathematics, particularly by those who promote the process of abstraction and conceptualization among students. The program emphasizes the importance of using various frameworks of studies for the same concept. In this regard, the study of equations and inequalities, the focuses program on the passage from the geometric framework «graphic» in the framework algebraic and vice versa.Our work is divided into two main parts: In the first part, we consider the effects to teacher's didactic/pedagogical choices and decision the mathematical knowledge. In the second part, we describe the example of algebra problem design on the factorization, development and resolution of equations. In conclusion, we collect the essential elements of the student's knowledge development.
\end{abstract}

Key words: Didactics Engineering -know- teach- Games of frames-change of frameworks and/or registers.

Résumé: Etant chargé d'enseigner les mathématiques au lycée, nous avons souhaité nous intéresser aux changements de cadres et/ou de registres dans l'enseignement des mathématiques, en particulier par ce que ceux-ci favorisent les processus d'abstraction et de conceptualisation de l'élève. Le programme insiste sur l'importance de l'utilisation des divers cadres d'études pour une même notion. Dans ce sens, l'étude des équations et inéquations, le programme insiste sur le passage du cadre géométrique "graphique " au cadre algébriques et vice-versa. Notre travail se scinde en deux parties :

Dans la première partie, nous envisageons les effets sur les choix et décisions des enseignants suivant que le savoir mathématique est ou n'est pas le principal enjeu de la relation didactique. Dans la deuxième partie, nous décrivons un exemple d'élaboration d'un problème d'algèbre portant sur la factorisation, le développement et la résolution des équations. En conclusion, nous regroupons des éléments essentiels de la progression du savoir chez les élèves.

Mots clés: Ingénierie didactique-savoir-enseigner-jeux de cadres-changement de cadres et/ou de registres.

\section{Introduction}

The findings come as a result of a study majoring in sciences questionnaires probing the failure of the student's in scientific subjects. Thanks to the different theories around the teaching-learning process, the materials of the disciplines, and more especially in mathematics, that this study have developed several guidelines in searching and analysis such failures. It is on this basis, along with the study of teaching knowledge low achievement rates in teaching and engaging students' capacity that we have chosen to town our interests.

Among multiple activities of mathematics teachers, in and outside classroom (preparation of lessons, exercises, exams, meetings with parents, advice for the class, etc...), only those in-class tasks and meetings with students will be considered.

The following taker the form of proposals that correspond to the didactic choices previously analyzed and argued. These proposals do not serve as a teaching model but as a backup that allows for a better understanding of the meaning and functionality of the proposed didactic tools proposed.

\subsection{Didactic Engineering:}

\section{Definition}

Didactic Engineering is a research methodology that determines the devices of teaching reproducible reporting. It refers to the existence of a description, a study and justifications, as accurate and consistent as possible, of the conditions of using this device. Didactics Engineering itself accompanies the devices produced a set of studies and analyses that give the characteristics of the product in reference to scientific theoretical and 
experimental knowledge at the moment. These studies may not be communicated to teachers, but they are indispensable for the analyses and observations of actual teaching. In the framework of scientific research, the engineering, to referred phenomenothecnical, aims at to introducing recommendations for teaching students, along with reproducing and didactic phenomena the study well of determined. This method is highly developed in the French research.

We refer interested readers to Mr. Artigue (1989).

Didactic Engineering is simply a product, the result of a priori analysis, and a process in which the teacher implements the product by adapting it, according to the dynamics of the class.

\subsection{Mathematical Knoweldge}

Knowledge in mathematics has a dual aspect. On the one hand, it has a functional availability of certain concepts and mathematical theorems to solve problems, to interpret new questions... In such a scientific operation, concepts and theorems of mathematics have a status of tool. The tools are registered in a context, under the action and the control of someone (or a group) at a given time. The situations or problems which the mathematical concepts evolve are the generators of meaning for these notions of a certain point of view that will be called semantics.

On the other hand, identifying concepts and theorems as elements of a corpus which is scientifically and socially recognized and formulating definitions, state of theorems and demonstrating then we confirm that the concepts and the mathematical theorems concerned have the status of an object. They are de-contextualisent, anonymized (even if they are designated by an proper noun) and A-temporal. The work of decontextualisation and depersonalization participates in the capitalization of knowledge.

The work of recontextualisating and the treating of the problems results in broadening sense to broaden the meaning. This does not preclude the capitalization of practices or particular knowledge, even provisionally.

Notions as well as theorems can be worked on, modified according to the situations in which they are solicited and lead to new concepts, in their turn, working matters, interpretations, modifications, generalizations... For theorems, we can explore the area of validity: imagining variants, the demonstrating, or on the contrary building counter-examples, to ensure that this is not possible. In any cases, it is led to relate different concepts. These connections are also seen as a source of meaning for those who realize them.

The mathematical work can be done with tools in the framework of a problem, such as on the objects, to extend the scope without specific purpose, or with an aesthetic concern. It necessary to respects a set of internal rules for mathematics. This is another component of the sense that we will call syntax.

The mathematical work is realized and communicated through in different interacting modes of expression.

\subsection{Teaching}

For a teacher teaching is to create the conditions that will produce knowledge among his students. " Regine douady "

\subsection{Learning}

For a student learning is to be involved in an intellectual activity that leads to long term availability of knowledge with its dual status of tool and object.

" Regine douady "

If we want teaching and learning to take place, knowledge must be considered as an important object, essential element in the exchange between the teacher and his students, because knowledge is an important element in schools.

The argument may be strong/reality. However, teachers are to choose adaptable knowledge setups for their students as well as for the learning overall learning aims.

\section{The Problem}

We have resumed the outlined problem in an article by $\mathrm{Mr}$ " Regine douady " chronical on mental calculation, a project in algebra with high school articulation".

The plain is marked by constituting two orthogonal graduated axes.

A. We are interested in the points of the plain whose the coordinates of witch $(x, y)$ are related:

$y=(x+3)\left(8-\frac{x}{2}\right)$

$\mathrm{E}$ being the set of the points.

1. Proposing 5 pairs of coordinates correspond to points of E and 5 Pairs of coordinates correspond to points of the plan do not belong to $\mathrm{E}$

2. Graphically represent the more possible points of E.

3. Are there points on $\mathrm{E}$ on the $\mathrm{x}$-axis? On the $\mathrm{y}$-axis ?

If so, give the coordinates of these points if possible. If not, say why.

DOI: $10.9790 / 7388-07020292100 \quad$ www.iosrjournals.org


4. Are there points of $E$ that have the same abscissa? The same coordinates?

If so, give examples. If not, say why.

B. We are now interested in the set $\mathrm{F}$ of the points of the point plain coordinated as follows $(\mathrm{x}, \mathrm{y}): \mathrm{y}=\mathrm{x}^{2}-9$ Answer the same questions as in A.

C. Is there any common point between $\mathrm{E}$ and $\mathrm{F}$ ?

So, if possible, give the coordinates of these points if possible.

\section{Competencies}

a. Supposed students skills to help understand the problem

i.Graphic Frame

- Draw orthogonal axes, graduate them;

- Mark points where known coordinates;

- Read the coordinates of the marked points;

- Correctly use the vocabulary: Marker, orthogonal axes, graduation, coordinates, $\mathrm{x}$-coordinate, $\mathrm{y}$-coordinate;

- Draw a curve of a second degree polynomial function;

- Orthogonal projection of a point on the two axes.

i.Algebraic Framework

- Substitute numeric values for letters in algebraic expressions and calculate their value;

- Develop polynomial algebraic expressions of the first or second degree or intervene factor products;

- Factor in very specific cases;

- Solve a first degree equation;

- Solve a second degree equation of with an indefinite.

- Make the Euclidean division if needed.

i.Digital Framework

- Compute well Calculate with the natural integers;

- Calculate precisely using the relative integers, the decimals, and fractions;

- Use a calculator as a calculation aid.

b. Framing the problem

The questions are in the graphical framework, for granted, the points are selected by an algebraic relationship. The digital framework is ambient. But students can solve the problem by changing the context of the problem in geometric or analytical framework or analytical.

\section{Means}

a. Conceptual means

The concepts implied in the supposed skills as explicit tools, include the implementation factor.

- The theorem " for a product of factors to be zero, it is necessary and sufficient that one its factors is zero" an implicit from dwin.

- The rapport between coefficients and root theorems" if the second degree equation $\mathrm{ax}^{2}+\mathrm{bx}+\mathrm{c}$ where the letters $\mathrm{a}, \mathrm{b}$ et $\mathrm{c}$ denote numbers, with a different from 0 , and being $\mathrm{x}$, The indefinite implies two solutions $\mathrm{x}_{1}, \mathrm{x}_{2}$ on a $\mathrm{x}_{1}+\mathrm{x}_{2}=-\frac{\mathrm{b}}{\mathrm{a}}$ et $\mathrm{x}_{1} \mathrm{x}_{2}=\frac{\mathrm{c}}{\mathrm{a}}$

- $\quad$ Remarkable identities.

- Orthogonal projection.

- To solve an equation with the following formula $f(x)=g(x)$ with $f$ et $g$ being two strictly-defined functions equivalent to seek the $\mathrm{x}$ coordinates of the points of intersection of the deus curves (Cf) et $(\mathrm{Cg})$.

\section{b. Technological tool}

The calculator; preferably programmable; allows once the working method are set, to program the calculator to maximize the number of $\mathrm{E}$ and obtain the coordinates of a large quantity of points of $\mathrm{E}$ and then $\mathrm{F}$ to have a geometric view of these sets or trace the curves of a digital function.

\section{The problem of variables}

a. Algebraic relations :

- $\quad$ Degree of the equation: 1 or 2 or 3 ;

- Written Expression: factorises or develops; the order of monomials : read from left to right, expressed first in $\mathrm{x}$ terms or first as the constant;

- The numeric coefficients : integers, non-integers, positives, negatives;

- The cancellation values. 
- The definition of the sets $\mathrm{E}$ and $\mathrm{F}$ as the curves of a second degree polynomial function or as sets of points $\mathrm{M}(\mathrm{x}, \mathrm{y})$ with the coordinates linked by an algebraic relation.

b. Graphics :

- The number of points to be marked : finite or infinite;

- The position of the points to select: anywhere on one of the axes within the limits of the material support of the graph or outside of these limits, outside of the axes but with a restrictive condition.

- The graduated marking axes are orthonormal or non-orthonormal axes,

c. Numericals :

Collecting and processing relevant and fraction of information related to use or not use a simple or programmable calculator: the treatment of the problem can be very different.

d. Order of the questions in the problem

\section{Didactic choice regulating setting the variables and the expectations of the teacher a. Part A}

The first expectation of the teacher is that students give meaning to the expression " $\mathrm{x}$ et $\mathrm{y}$ are linked by relations". To test this, we require placing 5 points whose coordinates verify the relations and 5 points which do not verify it. In case of difficulty, the teacher may initiate a discussion with the class on the given meaning to this expression and the set as an equation characteristic of a second degree polynomial function.

The second expectation concerns the knowledge more or less large points of. As we have said, the programmable calculator allows, once the method of work decided (substituting numerical values for the letters in the algebraic expressions and calculating their value), us to program the calculator and obtain the coordinates of a larger amount of points and of $F$ the graphic report $E$ of $F$ points enabling us to visualize geometric view of these sets.

This will later make it possible to design the common points in $\mathrm{E}$ and $\mathrm{F}$ as the points of intersection of the two curves.

The choice of two parabolas including the concavity is in the opposite direction and the vertices not too far from the other corresponds to a desire to facilitate among students the belief of existence geometric points of intersection. It will remain to make a technical work with the aid of algebraic tools, to know how to calculate the coordinates of these points, to actually prove the existence.

I have just described what is called a set of framework between the algebraic and graphical frameworks, exploiting in each of them what is easy and which, by transfer in the other, allows you to move forward in the problem.

\section{The third expectation is that students relate the following elements:}

- $\quad$ The point is on the $\mathrm{x}$-axis with its $\mathrm{y}$-coordinate equal 0 .

- Find out the values of $x$ which cancel $y$ with: Solve the equation $y=0$ and deduce a means to find the points $\mathrm{E}$ on the $\mathrm{X}$-axis.

- The chosen algebraic relation is written in the form of a product of two factors of the first degree to facilitate the search for the $\mathrm{x}$ values of solution of the equation $\mathrm{y}=0$.

However, given the students' familiarity with the developed expressions, we may think that a number of them will tend to develop the product of factors. However, these students do not know how to resolve the three of the second degree. The developed expression leads to an impasse, where some arrive to pull by bold amalgam!

The coefficients are chosen so that:

- One of the roots is equal to an integer small and can be found after a small number of tests of integer values for $\mathrm{x}$; and in the graphical framework a point of the two curves intersections their $\mathrm{x}$-coordinate will be easily find.

- The other to take a value large enough to escape the tests and corresponds to a point outside of the support sheet of the chart. It must then be explicitly solve an equation of the first degree; where to apply the relationship between coefficients and roots.

\section{The fourth is waiting, students transform a method:}

"I choose a value for $\mathrm{x}$ - coordinate, anyone I want to, I do my calculation in following the formula, I find the value of $\mathrm{y}$ - coordinate."

In a property of the relationship:

"Each value of x x - coordinate corresponds to a value of $\mathrm{y}$ - coordinate and only one."

And then to a characteristic of the whole E :

"Any value of $\mathrm{x}$ corresponds to a point of $\mathrm{E}$ and a single."

\section{b. Part B}

The application is similar to the previous one, but from an algebraic relation $\$$ which is a remarkable identity "difference of 2 squares". The teacher expects a very fast resolution to this part. His interest is two folds: 
- Evaluate the students on what they have learned from part A, and in any case, give them the opportunity to ask the same questions, whenever possible, to understand them better.

- The preparation of the Part C, real issue of the problem.

c. Part C

Students are asked to find out the common points of the two sets described respectively in A and B.

Graphically, a common point of $\mathrm{E}$ and $\mathrm{F}$ has coordinates $(\mathrm{x}, \mathrm{y})$ where $\mathrm{y}$ is expressed differently depending on $\mathrm{x}$ next to be thought of as a point $\mathrm{E}$ or point of $\mathrm{F}$.

Let consider these expressions $\mathrm{x}_{\mathrm{E}}$ and $\mathrm{y}_{\mathrm{F}}$, the previous job must in principle lead students to the algebraic translation of the question.

However, algebraically, it will be necessary for the " $="$ sign take a different meaning than it has been able to take during the study of the previous parts. Indeed, they-coordinate then was the result of a calculation and the "=" sign meant "has for result".

The reference Chart: A point has a single coordinate of contact information suggests writing $\mathrm{y}_{\mathrm{E}}$ and $\mathrm{y}_{\mathrm{F}}$ to express that the $\mathrm{y}$-coordinate to a common point to $\mathrm{E}$ and $\mathrm{F}$ can be written in two ways, which has nothing to do with the result of a calculation.

In addition, this equality is held only for the common points to $\mathrm{E}$ and $\mathrm{F}$. In other words, there are as many common points as values of $\mathrm{x}$ conducting this equality. Algebraically, this translates the resolution of an equation of the second degree containing terms of the $\mathrm{x}$ in two states. However it is a difficulty well marked by teachers and researchers on the subject, even if the equation is of the first degree.

To facilitate the task, we have chosen one of the points on the $\mathrm{x}$-axis so that it is part of the points already identified graphically in the two sets. It corresponds to $x+3=0$. seen the choices described above of the relative positions of the parabolas, the other point is visible graphically.

For that the resolution either algebraic necessary, it must choose the coordinates of this point, therefore the coefficients of the equations, so that they could not be found after a few empirical tests.

Thus, to solve the equation $x^{2}-9=(x+3)\left(8-\frac{x}{2}\right)$, the development and the consolidation of the terms of the same degree lead to the impasse, at least if the rules of algebraic calculation are respected. The expression of the first member in the form of product $(x-3)(x+3)$ is unavoidable; especially if the students do not know the relationship between the coefficients and the roots. The factorization is a tool which led to the resolution of two equations of the first degree, other algebraic tool available. The solution $\mathrm{x}=\frac{22}{3}$ of the equation $(x+3)\left(8-\frac{x}{2}\right)$ cannot be found by chance.

\section{Possible errors committed by the students:}

An obvious view of the problem, and as far as high school mathematics students can commit a lot of errors.

- Errors of calculates.

- Errors of thoughtlessness.

- Confusion of the roles of the variables $x$ et $y$.

- Substitution of numeric values for the letters in the algebraic expressions and calculate their value.

- Errors of tracing a mark of two axes graduated orthogonal, due to lack of knowledge of the words ( graduated orthogonal axes).

- Errors of misunderstanding the given questions.

- In particular they may produce invalid calculations mathematically as grouping terms of different degree if this allows them to achieve a response.

- The concept of transforming the relationship to an equation to solve, to determine the points of the $\mathrm{Y}$ axis and the points of the $\mathrm{x}$-axis.

- Poorly read the coordinates of a point on the curves of a function.

- $\quad$ Errors of knowledge.

- Errors oin reasoning.

- Errors of inattention.

- Errors in the use of non-existent theorems what is called theorem of students.

IX. Analysis of the copied for students:

As we have already said, this problem is proposed to a group of 24 common core students and to the 13 the first year mathematical sciences students because students at the end of the middle school did not have the opportunity to trace the curves of the polynomial functions of the second degree (it is not part of the program of mathematics has this level in Morocco).

a. Quantitative study :

We will show the results obtained by analyzing the responses of students to the problem 


\begin{tabular}{|c|c|c|c|c|}
\hline & \multicolumn{4}{|c|}{ Part A } \\
\hline & \multicolumn{2}{|r|}{ Common core } & \multicolumn{2}{|c|}{ First year of the bachelor's degree } \\
\hline & $\begin{array}{l}\text { Nb of wrong } \\
\text { answers. }\end{array}$ & $\begin{array}{l}\mathrm{Nb} \text { of right } \\
\text { answers. }\end{array}$ & $\begin{array}{l}\mathrm{Nb} \text { of wrong } \\
\text { answers. }\end{array}$ & $\mathrm{Nb}$ of right answers. \\
\hline Qst 1 & 11 & 13 & 13 & $\mathbf{0}$ \\
\hline Qst2 & 4 & 20 & 11 & 2 \\
\hline Qst3 & 3 & 21 & 11 & 2 \\
\hline Qst4 & 3 & 21 & 10 & 3 \\
\hline
\end{tabular}

\section{Part B}

\begin{tabular}{|l|l|l|l|}
\hline \multicolumn{2}{|c|}{ Common core } & First year of the bachelor's degree \\
\hline $\begin{array}{l}\text { Nb of wrong } \\
\text { answers. }\end{array}$ & Nb of right answers. & Nb of wrong answers. & $\begin{array}{l}\text { Nb of right } \\
\text { answers. }\end{array}$ \\
\hline
\end{tabular}

\begin{tabular}{|l|l|l|l|l|}
\hline Qst 1 & $\mathbf{1 6}$ & $\mathbf{8}$ & $\mathbf{1 3}$ & $\mathbf{0}$ \\
\hline Qst2 & $\mathbf{4}$ & $\mathbf{2 0}$ & $\mathbf{1 1}$ & $\mathbf{2}$ \\
\hline Qst3 & $\mathbf{4}$ & $\mathbf{2 0}$ & $\mathbf{1 1}$ & $\mathbf{2}$ \\
\hline Qst4 & $\mathbf{3}$ & $\mathbf{2 1}$ & $\mathbf{1 0}$ & $\mathbf{3}$ \\
\hline
\end{tabular}

Parti C

\begin{tabular}{|l|l|l|l|}
\hline \multicolumn{2}{|c|}{ Common core } & First year of the bachelor's degree \\
\hline $\begin{array}{l}\text { Nb of wrong } \\
\text { answers. }\end{array}$ & $\begin{array}{l}\text { Nb of right } \\
\text { answers. }\end{array}$ & $\begin{array}{l}\text { Nb of wrong } \\
\text { answers. }\end{array}$ & $\begin{array}{l}\text { Nb of right } \\
\text { answers. }\end{array}$ \\
\hline
\end{tabular}

\begin{tabular}{|l|l|l|l|l|}
\hline Qst1 & $\mathbf{6}$ & $\mathbf{1 8}$ & $\mathbf{1 2}$ & $\mathbf{1}$ \\
\hline Qst2 & $\mathbf{3}$ & $\mathbf{2 1}$ & $\mathbf{1 1}$ & $\mathbf{2}$ \\
\hline
\end{tabular}

Observation: If students do not respond to a question it is counted as a false answer.

\section{a. Qualitative Study:}

The students have committed many errors during the resolution of the problem :

\begin{tabular}{|c|c|}
\hline Error & Example \\
\hline \multirow[t]{2}{*}{$\begin{array}{l}\text { On the statement: } \\
\text { Poor understanding of the data. }\end{array}$} & $\begin{array}{l}\text { The proposed word } 5 \text { pair of } \mathrm{F}, \mathrm{y} \text { is linked by a relation with } \mathrm{x} \text { should not be } \\
\text { separated } \\
\text { The } \mathrm{y} \text { - coordinate of a common point to } \mathrm{E} \text { and } \mathrm{F} \text { can be written in two ways }\end{array}$ \\
\hline & $\begin{array}{l}(\mathrm{x}+3)(8-\mathrm{x}) / 2 \text { in place of }(\mathrm{x}+3)(8-\mathrm{x} / 2) \\
\mathrm{y}^{*} \mathrm{x}^{2}-9 \text { instead of } \mathrm{y}=\mathrm{x}^{2}-9\end{array}$ \\
\hline On the calculations: & Instead of 24 \\
\hline \multirow[b]{2}{*}{$\begin{array}{l}\text { Non-compliance of the priorities. } \\
\text { Non-compliance with the rules } \\
\text { Addition and subtraction }\end{array}$} & \\
\hline & $\begin{array}{l}\text { For } x=6 \\
\qquad y=(6+3)\left(8-\frac{6}{2}\right)=9 * 2 / 2=9 \\
\quad \text { Instead of } y=9 * 5=45\end{array}$ \\
\hline \multicolumn{2}{|l|}{ On the Course: } \\
\hline $\begin{array}{l}\text { Poor } \\
\text { the theorems (theorems students) understanding of }\end{array}$ & $\begin{array}{l}\text { xy-y } y=z \text { instead of } x=0 \text { ou } y=z \\
x^{2}-y^{2}=(x-y)^{2} \text { instead of } x^{2}-y^{2}=(x-y)(x+y) \\
\text { The descriminat of the equation } a x^{2}+b x+c=0 \text { and } \\
\Delta=a^{2}-4 b c \text { instead of } \Delta=b^{2}-4 a c \\
\text { More errors in determining of the coefficient of an second equation degree }\end{array}$ \\
\hline The curve of a polynomial function Second & $\begin{array}{l}\text { The representative curve of a polynomail function of the second level is astrought } \\
\text { instead of a parabola }\end{array}$ \\
\hline $\begin{array}{l}\text { The characteristic equation of the two axis } \\
\text { of the mark }\end{array}$ & $y$-axis and the \\
\hline Other & No Reference \\
\hline
\end{tabular}




\section{b. Examples of Errors}

\section{Example 1 :}

The points $M(x, y)$ of the set $F$ are the points whose coordinates by the relationship $y=x^{2}-9$

This student takes a point $M(a, b)$ already defined by their coordinates and calculate if

$$
K=b * a^{2}-9
$$

$K>0$ then $M(a, b) \in F$

Else $M(a, b) \notin F$

Confrontation between a curve of an

affine function and a curve of a

polynomial second degree function

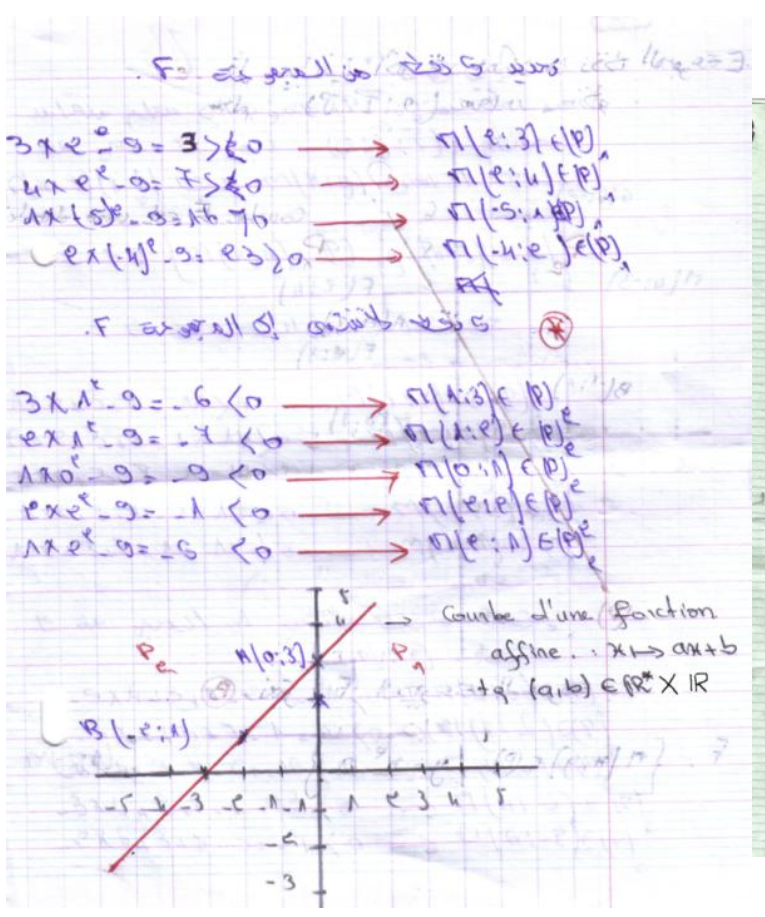

\section{Example 2 :}

In this example, it was
for $x=0$ the $y$-coordinate takes
the values in the interval $[0,25]$ of
same for $x=3,4,5$ the $y$ -
coordinate to two values and
for $x=6 ; y$ takes several value.
More
$x$ takes these value on the
Interval $[0,6]$
This student does not know the
definition of a function curve

\section{c. Diagnosis of the error}

In this problem, some students, to find the five points of the sets $E$ and $F$ and the five points that do not belong to $\mathrm{E}$ and $\mathrm{F}$ give a value to $\mathrm{x}$ and calculate from $\mathrm{y}$ the relationship which binds $\mathrm{x}$ et $\mathrm{y}$

If they found: If $\mathrm{y}>0$ then the point $\mathrm{M}(\mathrm{x}, \mathrm{y}) \in \mathrm{F}$.

\section{Else $\mathrm{M}(\mathrm{x}, \mathrm{y}) \notin \mathrm{F}$.}

Where they take a point $M(a, b)$ whose coordinates already defined and calculated $M(a, b)$ the number

$$
\begin{gathered}
\mathrm{K}=\mathrm{b} * \mathrm{a}^{2}-9: \quad \text { If } \mathrm{K}>0 \text { then the point } \mathrm{M}(\mathrm{a}, \mathrm{b}) \in \mathrm{F} \\
\text { Else } \mathrm{M}(\mathrm{a}, \mathrm{b}) \notin \mathrm{F}
\end{gathered}
$$

The second error of the same student and the confusion between a curve of an affine function and a curve of a second degree polynomial function. 
It seems that the main cause of this error is that these students do not sufficiently master the definition of a set and the definition of the characteristic equation of a curve of the second degree polynomial function, in particular they had not in the habit of working with the sets of the points of the plant such as their $\mathrm{M}(\mathrm{x}, \mathrm{y})$ coordinates $\mathrm{x}$ et $\mathrm{y}$ are linked by a relationship then this problem can be treated by another method we apply the curves of the polynomial functions second degree.

\section{Interviews}

\section{a. Interviews Guide}

In addition to the quantitative and qualitative results of the students' written productions to the asked questions, in relation to our problem, we have carried out interviews with these students for the purpose of complete our study.

It should be noted that during the talks, the questions were asked using the provided guide, but in a spontaneous manner. Each maintenance guide is discussed separately below.

It was organized around two axes:

\section{i. General questions.}

An introduction to thank students for having accepted the maintenance.

We want to know what is the importance of mathematics in the students daily life? and the relationship with other disciplines.

Do students have the habit and the experience of studying a mathematical problem with different frameworks and / or registres?

His relationship with students and their mathematics teachers.

i. Questions on the committed errors in the problem.

1. The resolution of a second degree equation.

2. Calculates the range of a real number by a numerical function.

3. Read the coordinates of a point of a plane fitted with a frame orthogonal.

4. Equation characteristic of a curve of a numerical function.

5. Recognize the graphical representation of a quadratic polynomial function.

6. Graphical representation of a quadratic polynomial function.

7. The geometrical interpretation of the resolution of the equation $\mathrm{f}(\mathrm{x})=0$ with $\mathrm{f}$ is a digital function.

8. The geometrical interpretation of the resolution of the equation $\mathrm{f}(\mathrm{x})=\mathrm{g}(\mathrm{x})$ with $\mathrm{F}$ and $\mathrm{G}$ two numerical functions.

- The intersection of two sets.

\section{ii. Statistical result of maintains}

iii.

\begin{tabular}{|l|l|l|l|l|}
\cline { 2 - 5 } \multicolumn{1}{c|}{} & \multicolumn{2}{c|}{ Common core } & \multicolumn{2}{c|}{$\begin{array}{c}\text { First year of the } \\
\text { bachelor's degree }\end{array}$} \\
\cline { 2 - 6 } \multicolumn{1}{c|}{} & Nb of Ans & Nb of Ans & Nb of Ans & Nb of Ans \\
\hline Competency & Acquired & Not Acquired & Acquired & Not Acquired \\
\hline $\mathbf{1}$ & $\mathbf{2 0}$ & $\mathbf{4}$ & $\mathbf{1 3}$ & $\mathbf{0}$ \\
\hline $\mathbf{2}$ & $\mathbf{2 4}$ & $\mathbf{0}$ & $\mathbf{1 3}$ & $\mathbf{0}$ \\
\hline $\mathbf{3}$ & $\mathbf{2 0}$ & $\mathbf{4}$ & $\mathbf{1 3}$ & $\mathbf{0}$ \\
\hline $\mathbf{4}$ & $\mathbf{3}$ & $\mathbf{2 1}$ & $\mathbf{1 0}$ & $\mathbf{3}$ \\
\hline $\mathbf{5}$ & $\mathbf{1 0}$ & $\mathbf{1 4}$ & $\mathbf{1 1}$ & $\mathbf{2}$ \\
\hline $\mathbf{6}$ & $\mathbf{1 5}$ & $\mathbf{9}$ & $\mathbf{1 2}$ & $\mathbf{1}$ \\
\hline $\mathbf{7}$ & $\mathbf{4}$ & $\mathbf{2 0}$ & $\mathbf{9}$ & $\mathbf{4}$ \\
\hline $\mathbf{8}$ & $\mathbf{4}$ & $\mathbf{2 0}$ & $\mathbf{9}$ & $\mathbf{4}$ \\
\hline $\mathbf{9}$ & $\mathbf{3}$ & $\mathbf{2 1}$ & $\mathbf{1 0}$ & $\mathbf{3}$ \\
\hline
\end{tabular}

According to the analysis of the students' responses to the oral questions of the interview we find that each student has a specific notion of its own of a curve in its head, its own concept of curve, different from one student to another; and distinct has our own as teachers and the responses of the students do not come at random. We often spoke of "Errors of thoughtlessness» but the students answers by using "Theorems ". Although wrong for the teacher that we sum up, and not explained to students (in most cases), these theoremstudents have for the status of theorem. They enable him to make a response to the questions asked Example: whatever the real numbers $\mathrm{x}, \mathrm{y}, \mathrm{z}$ we have $\mathrm{xy}=\mathrm{xz} \quad \Leftrightarrow \quad \mathrm{y}=\mathrm{z}$

For a student of first year in high school a curve of a function and always a straight line.

In other cases, students do not know change the framework of an exercise; student does not know how to apply a programmed calculator to draw the curve of a function. In addition, they do not have the ability to treat the exercise as were asked to change the framework and install it as we have showed it here: 


\section{The problem reformulation :}

Are $\mathrm{f}$ and $\mathrm{g}$ two numerical function defined by:

$$
\begin{aligned}
& f(x)=x^{2}-9 \\
& g(x)=(x+3)\left(8-\frac{x}{2}\right)
\end{aligned}
$$

A.

$(\mathrm{Cf}),(\mathrm{Cg})$ The successive waves of functions $\mathrm{f}$ and $\mathrm{g}$ in an frame orthonormal $(\mathrm{O}, \overrightarrow{\mathrm{OI}}, \overrightarrow{\mathrm{OJ}})$

1. Suggest 5 pairs of coordinates corresponding to points of the curve (Cf) and 5 pairs of coordinates corresponding to the points of the plan not belonging to (Cf).

2. Graphically represent the curve (Cf).

3. Are there points $(\mathrm{Cf})$ on the $\mathrm{x}$-axis? On the y-axis?

If yes, give the coordinates of these points if possible. If not, say why.

4. Are there points of $(\mathrm{Cf})$ which have the same $\mathrm{x}$ - coordinate? The same $\mathrm{y}$-coordinate?

If yes, give examples. If not, say why.

B. Answer the same questions as A has for the Curve $(\mathrm{Cg})$.

C. Is there any common points to $(\mathrm{Cf})$ and $(\mathrm{Cg})$ ?

If yes, give the coordinates of these points if possible.

\section{Conclusion:}

The engineering presented above is an example of a setting in scene of the dialectical tool-object. We have worked with our common core students and the first year of the bachelor's degree to see in what framework should install the problem and what the influence of success rates among students. In this work, the operation of frameworks and/or registers or change of points of view within a framework plays a key role

According to the statistical analysis of the students' productions and the maintenance we have done with them we draw the following main conclusions:

Concerning the treatment of registers, the majority of students face problems in discussion, especially when it comes to algebraic register towards the geometric register, here in our case the geometric register presented by the global aspect that is the curve of a numerical function, it is a cognitive and educational epistemological difficulty. For student to be able to carry out tasks related to treatments and changes of frameworks and /or registry, he/she must receive a diversity and a multitude of activities related to these tasks, to relate between the various registers of the same function with activities having the objective of moving from one register to another. In the chapters dealing with functions, special emphasis must be on the link between the geometrical appearance (point on a curve) and the analytical aspect (coordinates checking an equation of the curve). This line is not at all perceived by the majority of students.

Concerning the functions subject, it is clearly requested that the student has to be able to study a problem with different frameworks and/or registers. "Explaining, different aspects (graphic, calculation, geometric...). That's why, it is suggested to insist on the respective contributions of the various frameworks and / or study registers.

Moreover, it is interesting to suggest exercises or problems causing changes of frameworks and / or registers using different representations of the same mathematical object.

To be effective, an objective must be operationalized (describe as much as possible the obtained result). For this, the statement of the problem must define:

The conditions: The statement should mention the conditions in which the concept is expected.

The level of requirement: The statement must indicate the level of requirement, the criteria that will be used in the learning evaluation.

\section{Bibliographical References}

[1]. Artigue,Mr. $\left(1989^{\circ}\right)$. Didactics Engineering .Search in didactics of mathematics, Vol 9,No.3, $282-307$

[2]. Brousseau, G. (1986) the epistemological obstacles and the didactics of mathematics.

[3]. Brousseau, G. The foundations and methods of the didactics of mathematics .

[4]. Brousseau, G. (1998). Theory of Didactical Situations; research in didactics of mathematics (The Wild thought,

[5]. Chevallard, Y. (1985). The didactic transposition of the learned knowledge in the taught knowledge. The wild thought. Grenoble.

[6]. Chevallard, Y. The fundamental concepts of the didactics: prospects made by an anthropological approach.

[7]. Conne, F. Knowledge and knowledge in the perspective of the didactic transposition.

[8]. Douady R. (1994). Didactics Engineering and evolution of the report to know a chronic in mental calculation, a project in algebra to the articulation college-second .

[9]. Duval, R. (1988). Graphics and equations: the articulation of the two registries, Annals of didactic and Cognitive Sciences 1 IREM of Stasbourg .

[10]. El Maroufi, Ab. Mouradi,Med. Zarhouti, Kh. (2016). Diagnosis of the obstacles as for the graphical representation by the TGN and the questionnaire 2320-737X V 6 (IOSR-JRME) .

[11]. Pedeches, P. (2010). The evaluation, pilot of the didactic contract (memory of Master 2e year Research University of Toulouse). 